by Robert Wolf

\title{
Budget Crisis: A Review of Perpetual Access
}

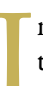
$\mathrm{n}$ years past, prior to the e-journal boom, when times got tough, libraries were forced to cut subscriptions to some of their journal titles. You can see the after effects of these cuts in many print runs. You can almost read the bad budget years by the gaps in a collection much like a biologist can read the rings of a tree to determine the weather conditions of that year. However, in the days of the e-journal subscription things are different and I'm not so sure they have gotten better. Libraries have become more and more dependent on e-journals, e-journal packages, and databases to fill in their journal collections. But what happens when we can no longer afford to pay for these subscriptions? What happens to our access?

Some of our subscriptions have an archival or perpetual access provision but some do not. Most of the journal access through our aggregator databases, such as Ebsco's Academic Search Complete or Gales Academic OneFile, will be lost if we cancel our subscriptions. They are built on a lease model where we pay for access to the information but we never actually own it. These databases make up a significant percentage of many libraries' journal collections. At my library 33,210 out of 38,157 titles or $87 \%$ fall under this category.

Another source of e-journal subscriptions is through publisher packages where libraries typically have limited access to all or most of a particular publisher's journal titles, but at a fraction of the cost. Many of these collections have archival provisions which allow you to archive the years you subscribed to. For instance we subscribe to a Wiley title package that gives us access to all Wiley titles back to 1995 . Let's say we started this subscription in 2003. If we were to cancel this subscription we would have perpetual access to all journals published between 2003 and 2009. We would lose the added back files which part of the subscription, unless we had purchased them separately.

The third subscription method is on a title-by-title basis directly from the publishers and usually has an archival provision. Since this is done on a title-bytitle basis it would be impossible to make a general statement.

So how do we get perpetual access? What format does it come in? What can we do with it? A quick review of your license agreement can give you most of these answers, though they are not always very helpful as you can see from the archival provision for Project MUSE.
"Approximately 90 days after the expiration of an annual subscription term, Project MUSE $^{\bullet}$ will provide the Subscriber, upon request, an archival (non-searchable) file on DVD-ROM or other appropriate media as determined by Project MUSE ${ }^{*}$, containing the content of all issues published online during the 12-month subscription term."1

There is usually a process to follow and a time period in which to do it in order to get your archives. Publisher X might supply an archival copy of your journal holdings on a DVD, but you will have to request this DVD within thirty days of cancellation, while Publisher Y will send the data on a DVD or other unknown format, ninety days after cessation of payment. Some publishers will also give you the option to download the content from their server, will host your content for a specified time period, allow you to use their server and search interface for a fee or free, or even allow a third party to host your data. The data may come in the form of PDFs, html, text, an XML file, or other format. ${ }^{2,3}$

Great so what do you do with it once you get your archival copy? Ideally the publisher would continue to provide access for you, but in most cases you would need to have your own server or server space where you could upload the content. The server would have to be secure and limit access only to your patrons, after all just because you purchased the archival rights does not mean you can offer access to these journals to anyone you please. This would not be a simple process of inserting a DVD and loading some software, rather it would require a certain level of planning and technical expertise on your part.

Let's pretend you were able to load the data to a local server, how do your users access it? More than likely you're not going to have the interface you had when you were a paying customer, in fact you're not going to have an interface at all. You will most likely just have data. If you participate in LOCKSS, CLOCKSS or Portico, you might think you have a solution, but you still don't have access to the search capability of the original interface.

LOCKSS simply allows you to backup data from the publisher's site, but still requires you to have a subscription to the site to use their search interface. It can integrate with your Open URL link resolver but patrons would need to find the citation information another way. ${ }^{4}$ CLOCKSS, like LOCKS is another dark archive meant for long term preservation of digital resources, it too is not meant to be a hosting service for your electronic holdings. ${ }^{5}$
Portico only allows access to your archives under very particular circumstances, none of which protect an institution from loss due to a lack of financial difficulties. In order to access your Portico one of the following must happen, the publisher stops operations, or the publisher ceases to publish a title, or publisher no longer offers back issues, or upon catastrophic and sustained failure of a publisher's delivery platform. ${ }^{6}$

Oh and did I mention that LOCKSS, CLOCKSS and Portico only have archive rights to a select group of publishers? Unfortunately, none of these solutions where designed to handle simple subscription cancelation, but rather they act as insurance policies against disaster and provide longer archival integrity. Many smaller libraries like my own will have large archives with no way to access them. If you're library has its own server and someone who can create some sort of access interface then maybe you're ok.

So where does this leave us and why am I bringing this up now? For many libraries this is the first major financial crisis we have faced since the wholesale acceptance of electronic journals as a viable alternative to print. We have spent the last decade building our electronic journal subscriptions without seriously considering the real obstacles to perpetual access. We know publishers offer perpetual access, and that is good, however we have not taken the steps necessary to ensure that it is in a format we can actually use. We need to work with publishers to provide reasonable standards and expectations for perpetual access. Without this we will continue to build our holdings without any assurance for the future.

\section{References}

${ }^{1}$ Project MUSE. http://muse.jhu.edu/

2 Stemper, J. Barribeau, S., "Perpetual Access to Electronic Journals: A Survey of One Academic Research Library's Licenses." Library Resources \& Technical Services, 50:2 (2006): 91-109.

${ }^{3}$ Sam Rogers, "Survey and Analysis of Electronic Journal Licenses for Long-Term Access Provisions in Tertiary New Zealand Academic Libraries." Serials Review, 35: 1, (2009): 3-15.

${ }^{4}$ LOCKSS. http://www.lockss.org/lockss/Home 5 CLOCKSS. http://www.clockss.org/clockss/ Home

${ }^{6}$ Portico: A digital preservation and electronic archiving service. http://0-www.portico.org.uncclc. coast.uncwil.edu 